\title{
$X I$. The effect of high temperatures on the rate of decay of the active deposit from radium
}

\section{Howard L. Bronson Ph.D.}

To cite this article: Howard L. Bronson Ph.D. (1906) XI. The effect of high temperatures on the rate of decay of the active deposit from radium , Philosophical Magazine Series 6, 11:61, 143-153, DOI: $10.1080 / 14786440609463432$

To link to this article: http://dx.doi.org/10.1080/14786440609463432

曲 Published online: 16 Apr 2009.

Submit your article to this journal $\sqsubset \pi$

Џ Article views: 3

Q View related articles $\square$

Citing articles: 5 View citing articles 5 


\title{
$\left[\begin{array}{ll}143 & ]\end{array}\right.$
}

XI. The Effect of High Temperatures on the Rate of Decay of the Active Deposit from Radium. By Howard L. Bronson, Ph.D.**

\begin{abstract}
A PRELIMINARY account of the method and some of $A$ the results obtained have already been given in the American Journal of Science for February and July 1905. As the method is new and has proved very satisfactory in obtaining the decay curves of radioactive substances, it is here given in some detail.
\end{abstract}

\section{Apparatus and Method.}

In the ordinary method of comparing ionization currents by an electrometer, the rate of movement of the needle is taken as a measure of the current. In doing this, it is assumed that the capacity of the system and the lag of the needle behind the potential is the same for different rates. These assumptions may, in some cases, be warranted, but they certainly are not when the currents compared differ greatly in magnitude, or when the needle is moving rapidly. In the latter case capacities may be added in parallel, which reduces the rate of movement, but sreates the difficulty of comparing capacities. This takes time and is never entirely satisfactory. A still greater difficulty is experienced with the " rate" method, when rapidly changing ionization currents are to be measured, because, from the nature of the method, the observations can be neither instantanejus nor taken in rapid succession. The desirability, therefore, of a more direct and rapid method of measurement is evident.

The following method, suggested by Professor Rutherford, has been found by the writer to be very convenient and satisfactory for all radioactive measurements thus far attempted. The theory of the method is as follows :-

The arrangement of the apparatus, as seen in fig. 1 (p. 144), differs only from that ordinarily used in having one pair of quadrants of the electrometer connected not only to the testing vessel, but also to earth through a very high resistance. It is evident in this case that, when the key is closed, the ionization current from the testing vessel will continue to increase the potential-difference of the quadrants until the conduction current through the high resistance becomes equal to the ionization current. Since this conduction current is proportional to the potential-difference, it follows that, when equilibrium is reached, the ionization current also will be proportional to it. If the electrometer is well adjusted, the

* Communicated by Prof. E. Rutherford, F.R S. 
defexions, when small, will be proportional to the same potential-difference of the quadrants. This makes a simple direct-reading instrument.

Fig. 1.

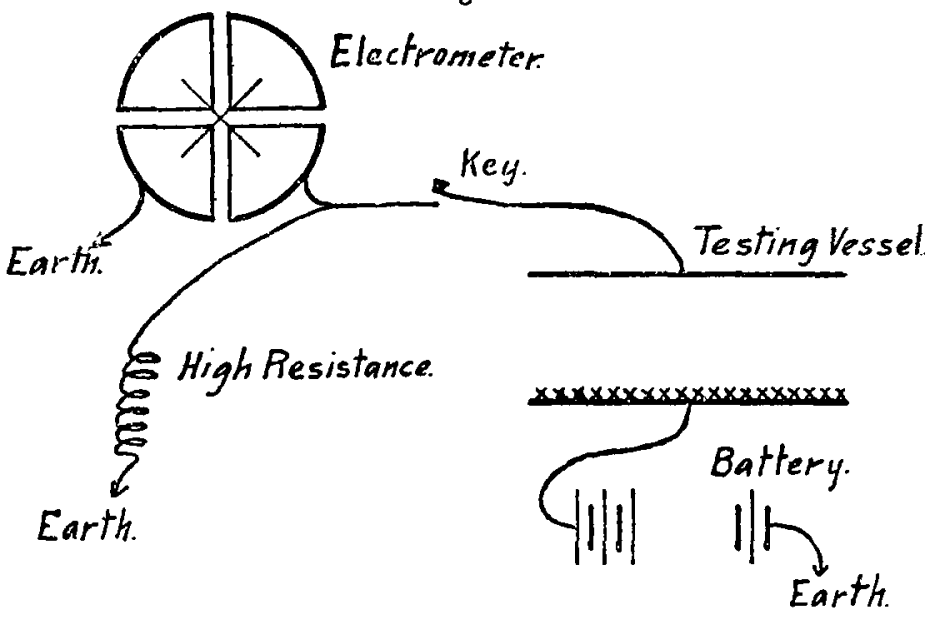

Resistances of the order of $10^{11} \mathrm{ohms}$ made of amyl alcohol and carbon on glass were tried, and gave results which compared favourably with those oblained by the " rate" method. The results, however, were not satisfactory, because the resistances did not remain sufficiently constant. This was probably due in one case to polarization, and in the other to temperature changes. Professor Rutherford then suggested the possibility of using an ionization current in place of the conduction current through a high resistance. The possibility of doing this is due to the fact that the ionization current through a gas, subject to a constant source of ionization, is proportional to the potential-difference between the plates when this potential-difference is small. Any strongly radioactive substance which will remain approximately constant during the time of a single experiment can be used as the source of ionization. In the present case a very radioactive bismuth plate from Dr. Sthamer of Hamburg was used. The activity of this plate was due to a deposit of the so-called radiu-tellurium of Marck wald, and has the advantage of not giving out any penetrating rays. If, for example, radium had been used, it would have been necessary to surround the vessel in which it was placed with a shield of lead of considerable thickness, in order to prevent any disturbance by the penetrating rays. 
The advantages of this "constant deflexion" method are obvious: deflexions are independent of the capacity, and testing vessels may therefore be interchanged without error, measurements can be made over a wide range without any difficulty, and observations can be taken instantaneously and in as rapid succession as desirable. In some cases they were taken at five-second intervals.

The precision of an individual measurement is, however, limited by a slight oscillation of the needle. Repeated attempts have been made to eliminate this by better shielding from external electrostatic action, and by careful attention to contacts, but all to no purpose. The most probable explanation seems to be that it is due to exceedingly small and rapid changes in the ionization current itself. This difficulty, however, is not serious, for it seldom causes an error in a single observation of as much as one per cent.

In the actual carrying out of the experiments the following arrangement of apparatus was found to be the most convenient and satisfactory :-

Fin. 2.

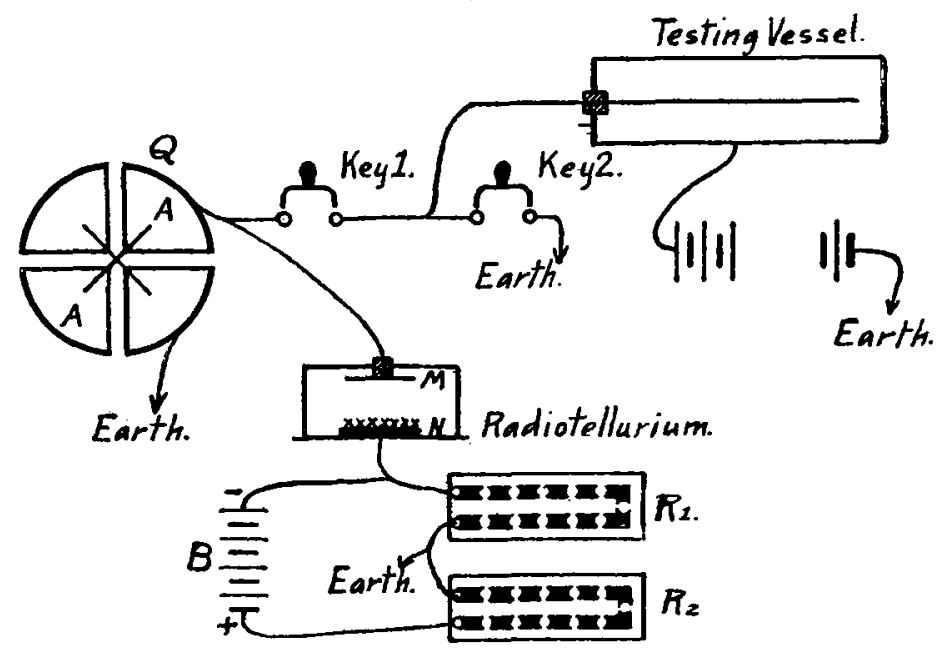

The electrometer was of the ordinary quadrant type, except that it was fitted with a very light needle of silvered mica, suspended by a fine phosphor-bronze wire. The needle was permanently connected to a battery of small accumulators, which kept its potentiai constant. As ordinarily used the needle was kept at a potential of 85 volts, and gave a deflexion of $15 \mathrm{~cm}$. for a potential-difference of 1 volt. Phil. Mag. S. b. Vol. 11. No. 61. Jan. $1906 . \quad$ I. 


\section{Dr. H. L. Bronson : Effect of High Temperatures on}

between the quadrants. By the use of a finer suspensionwire and a higher voltage on the needle, it was possible to increase this sensitiveness nearly one-hundred fold. The scale was $100 \mathrm{~cm}$. in length and only $180 \mathrm{~cm}$. from the electrometer, but it was possible, by turning it at a slight angle, to make the deflexions over its whole length proportional to the potential-difference of the quadrants, with a maximum error of not more than one half of 1 per cent. In case the current to be measured produced a deflexion larger than $100 \mathrm{~cm}$., a modification of this arrangement was adopted. By means of the battery $B$ and the two resistances $R_{1}$ and $R_{2}$, the potential of the radio-tellurium plate was brought below that of the earth. This reduces the potential-difference between the quadrants by the same amount, and thus makes the deflexions measurable on the scale. In this way ionization currents large enough to produce a deflexion of $150 \mathrm{~cm}$. could be measured. At this point a limit was reached, because larger currents than this through the radio-tellurium vessel were not proportional to the potential_difference between the plates. No doubt with a more active substance, such as radium bromide, the currents would remain proportional through a still larger range.

Both the radio-tellurium and the plate $M$ above it were covered with very thin aluminium-foil, to eliminate as far as possible any contact potential-difference; and the whole was enclosed in a metallic vessel to prevent electrostatic or air disturbances. In order to correct for the small contact potentialdifference, which always remained, an extra key was introduced between the testing vessel and the electrometer. When both keys were closed the testing vessel and all four quadrants of the electrometer were connected to earth; when key 2 was open the earth connexion was broken and the testing vessel was connected with the electrometer; when key 1 was open the earth connexion of quadrants A A was broken, and the reading then obtained was the true zero, and eliminated any error due to contact potential-differences. The entire apparatus was carefully surrounded by a metallic screen to eliminate any electrostatic disturbance, the keys being mechanically worked from without.

\section{Results oltained by Curie and Inanne.}

In the course of a careful investigation of the rate of decay of the active deposit from radium, an attempt was made to see whether it was permanently changed by high temperatures. The conclusion arrived at, contrary to that of Curie and Danne*,

* Comptes Rendus, cxxxriii. p. 748 (1904). 
is that temperatures between $700^{\circ}$ and $1100^{\circ} \mathrm{C}$. do not permanently alter the rate of decay of the active deposit.

Miss Gates * showed that when a platinum wire covered with the active deposit from radium is raised to a white heat, the active matter is removed from the platinum wire and deposited on cooler bodies in the neighbourhood. Curie and Danne still further extended our knowledge by showing that the constituents of the active deposit were not equally volatile. In addition, they also found that the rate of decay had apparently been permanently altered by the high temperature. The following table gives some of their results :-

\begin{tabular}{c|c}
$t$. & $\theta$. \\
$630^{\circ}$ & $29 \cdot 3$ \\
830 & $24 \cdot 6$ \\
1000 & $21 \cdot 0$ \\
1100 & $20 \cdot 3$ \\
1250 & $24 \cdot 1$ \\
1300 & $25 \cdot 4$
\end{tabular}

Here $t$ is the temperature in degrees centigrade to which the active deposit was raised, and $\theta$ is the "period," that is the time in minutes required for the activity to fall to hali value. Curie and Danne also state that the curves were all exponential. They conclude from this that the rate of decay has been permanently altered, and that, as the temperature is raised, the period reaches a minimum, at about $1100^{\circ} \mathrm{C}$., and then begins to increase again. It was not unnatural to expect that high temperatures should decrease the period of the active deposit, but it seemed very remarkable that the period should reach a minimum and then increase again when still higher temperatures were used.

\section{Results of the present Research.}

It seemed possible that all the results of Curie and Danne might be accounted for by the difference in volatility of the constituents of the active deposit. In order to see whether this were the case, a copper wire on which the active matter had been deposited was sealed in a piece of glass combustiontubing, which entirely prevented the escape of any volatile products. By exhausting the tube before sealing, it was found that it would stand temperatures high enough to melt the copper wire inside, that is, temperatures of at least $1100^{\circ} \mathrm{C}$.

In all cases where high temperatures were employed the

* Physical Review, May 1903.

$$
\mathrm{L} 2
$$


148 Dr. H. L. Bronson : Effect of High Temperatures on

wires were heated in a small electric furnace, made by Dr. C. A. Timme of Berlin. A calibration curve for the furnace had previously been made by the use of a platinum-rhodium thermo-junction. The wires were left in the furnace different lengths of time in different experiments, but this seemed to have very little effect on the result. On removal from the furnace, the glass tube containing the wire was covered with thin aluminiam-foil and placed in the bottom of a cylindrical testing vessel with a central electrode. In this case the ionization was produced by the $\beta$ rays alone. In those cases where the wire was heated without being sealed in a glass tube, the wire itself was made the central electrode of the testing vessel. Sometimes it was covered with a sufficient thickness of lead-foil to cut off all the $\alpha$ rays, but generally it was left uncovered, in which case the ionization was largely produced by the a rays. As the curves were the same in either case, it will be unnecessary to mention which method was taken in any particular experiment.

$\mathrm{B}$, fig. 3 , is the logarithmic decay curve, obtained when

Fig. 3.

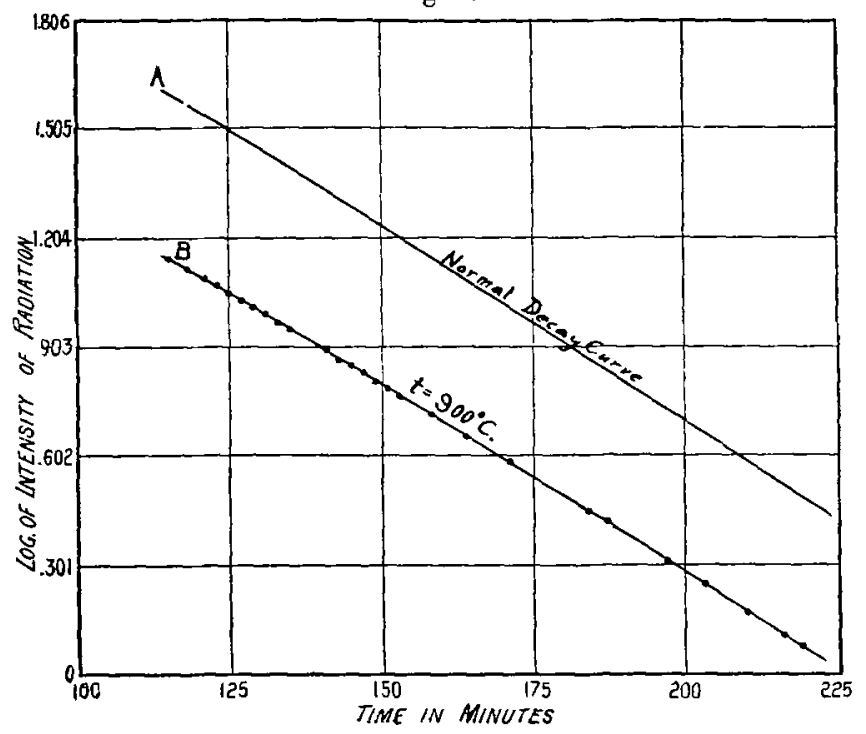

the active deposit was sealed in a glass tube and heated to $900^{\circ} \mathrm{C}$., and $\mathrm{A}$ is the decay curve for the active deposit which has not been subjected to a high temperature. These curves are approximately parallel, showing that the rate of decay was not measurably changed by a temperature of $900^{\circ} \mathrm{C}$. 
A large number of experiments were made in this manner using temperatures varying from $700^{\circ}$ to $1100^{\circ} \mathrm{C}$., but in no case did the period fall below twenty-six minutes.

If then, as the above experiments seem to show, the results of Curie and Danne are to be explained by the volatilization of one or more of the constituents of the active deposit, we should not expect to find the period of that part of the active matter remaining on the wire a function merely of the temperature, for other conditions besides temperature ought to affect the amount of volatilization, and this was found to be the case. For example, the removal of the volatile products, by blowing a current of air through the furnace or by inserting a cold copper rod for a few seconds before removing the platinum wire, always diminished the period of the matter remaining on the wire.

Fig. 4 is a fair example of the results obtained when the active matter is deposited on a platinum wire and heated in the furnace.

Fig. 4.

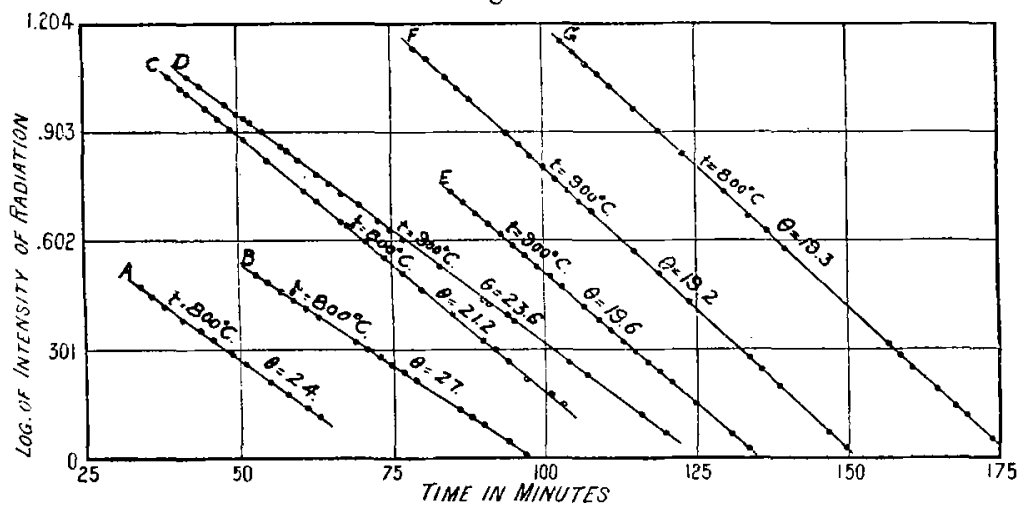

$A, B, C$, and $G$ are four decay curves of the active deposit, which had been previously heated to about $800^{\circ} \mathrm{C}$. In the case of the other three curves, the temperature used was about $900^{\circ} \mathrm{C}$. The time is reckoned from the removal of the wire from the emanation. The first points on curves $F$ and $G$ should be at about 200 and 300 minutes respectively, as in these cases the wires were not placed in the furnace for several hours after their removal from the emanation. As was expected, the period was found to vary considerably, but it was always smallest when care was taken to remove the volatile matter from the furnace before removing the wire. A large number of other curves were taken both at lower 


\section{Dr. H. L. Bronson: Effect of High Temperatures on}

and higher temperatures, but always with similar results. There was, however, one fact very noticeable among all the curves taken, especially among those where care was taken to remove the volatile products, namely, that a large number of them had periods between nineteen and twenty minutes. The only explanation of this seemed to be that there was left on the wire in these cases a simple radioactive substance, which gave out "rays" and decayed to half value in about nineteen minutes.

Now Rutherford* has shown that, neglecting the first half-hour, the decay curve of the active deposit from radium is satisfactorily explained by assuming two successive products, radium $B$ and radium $C$; the matter $B$ giving rise to no rays, and the matter $\mathrm{C}$ to $\alpha, \beta$, and $\gamma$ rays. Taking twentyeight minutes as the period of one of these, he calculated that the period of the other must be twenty-one minutes. Theoretically it makes no difference whether the longer period belongs to the matter $\mathrm{B}$ or $\mathrm{C}$, but the above-mentioned experiments of Curie and Danne supplied the evidence that caused him to decide that the longer period belonged to radium C.

The results given in this paper, on the contrary, seem to turnish conclusive evidence that radium $B$ has the longer period. In this case radium becomes analogous to thorium and actinium, each of which has a rayless change of longer period than the change immediately following.

There is still one point to be explained. Curie and Danue state that their curves are exponential, and the curves in fig. 4 would seem to confirm this. Now if the different periods obtained are due to a mixture of two substances in various proportions, one of which gives rays and has a period of nineteen minutes, and the other of which gives no rays and has a period of twenty-six minutes, then it is evident that the rate of decay of the mixture must keep decreasing, because the matter having the longer period decays more slowly, and therefore the proportion of it present in the mixture must keep increasing. In order to settle this point, the decay of the activity of the heated deposit was measured over a long: period.

Fig. 5 shows the result of two experiments of this kind. $1 \mathrm{~A}, 1 \mathrm{~B}$, and $1 \mathrm{C}$ are three sections of the same curves, obtained after heating the active deposit to about $650^{\circ} \mathrm{C} .1 \mathrm{~A}$ was taken immediately after heating, $1 \mathrm{~B}$ after about two hours, and $1 \mathrm{C}$ after about four hours. The respective values of the period were $22 \cdot 4,23 \cdot 6$, and $25 \cdot 5$ minutes. In the case

* Philosophical Transactions, vol. cciv. p. 196. 
of curve 2 , the temperature was about $800^{\circ} \mathrm{C} .2 \mathrm{~A}$ was taken immediately after heating, $2 \mathrm{~B}$ after about one hour, and $2 \mathrm{C}$ after about two and a half hours. The values obtained for

Fig. 5.

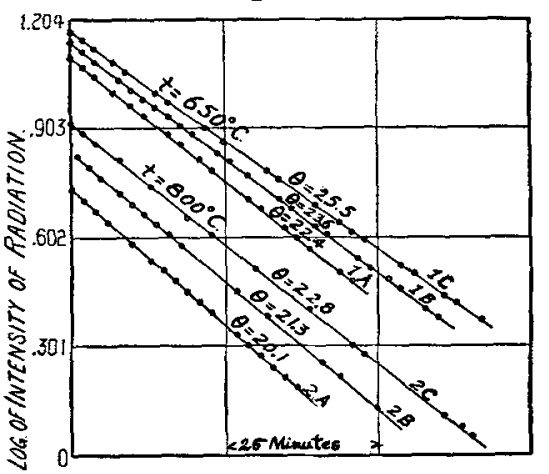

the period were respectively $20 \cdot 1,21 \cdot 3$, and $22 \cdot 8$ minutes. Thus it is seen that the curves obtained after heating the deposit were not exponential but had a continually increasing period.

\section{Decay Curve of the Excited Activity from Radium.}

Although 19.2 and 19.3 minutes, calculated from $F$ and $G$ (fig. 4), are the lowest values obtained for the period of radium $C$, yet even in these cases it would seem probable that all of radium $B$ had not been removed, and therefore that the true period of $\mathrm{C}$ was not over 19 minutes. It would seem of interest to check the above value of the period of radium $\mathrm{C}$ by comparing the experimental decay curve with the theoretical curve, calculated on the assumption that the period of radium $\mathrm{C}$ is nineteen minutes. The period of the final part of the decay curve of the active deposit from radium: is usually taken as about twenty-eight minutes. This is about the correct value for the period two and a half hours after the removal of the active deposit from the presence of the emanation. If, however, the period is measured after five or six hours, it will be found to be considerably less.

Fig. 6 shows the final part of four decay curves. The first point on each curve is more than four and a half hours after the removal of the active deposit from the emanation; yet even in these cases the curves are not exactly exponential. These curves give 26.1 minutes as the mean value of the period of the active deposit between five and seven hours after its removal from the emanation. From this it can be 
152 Dr. H. L. Bronson: Effect of High Temperatures on easily calculated that the final period of decay, that is the period of radium $\mathrm{B}$, is about 25.8 minutes. The experimental results are not accurate enough to make the last ligure

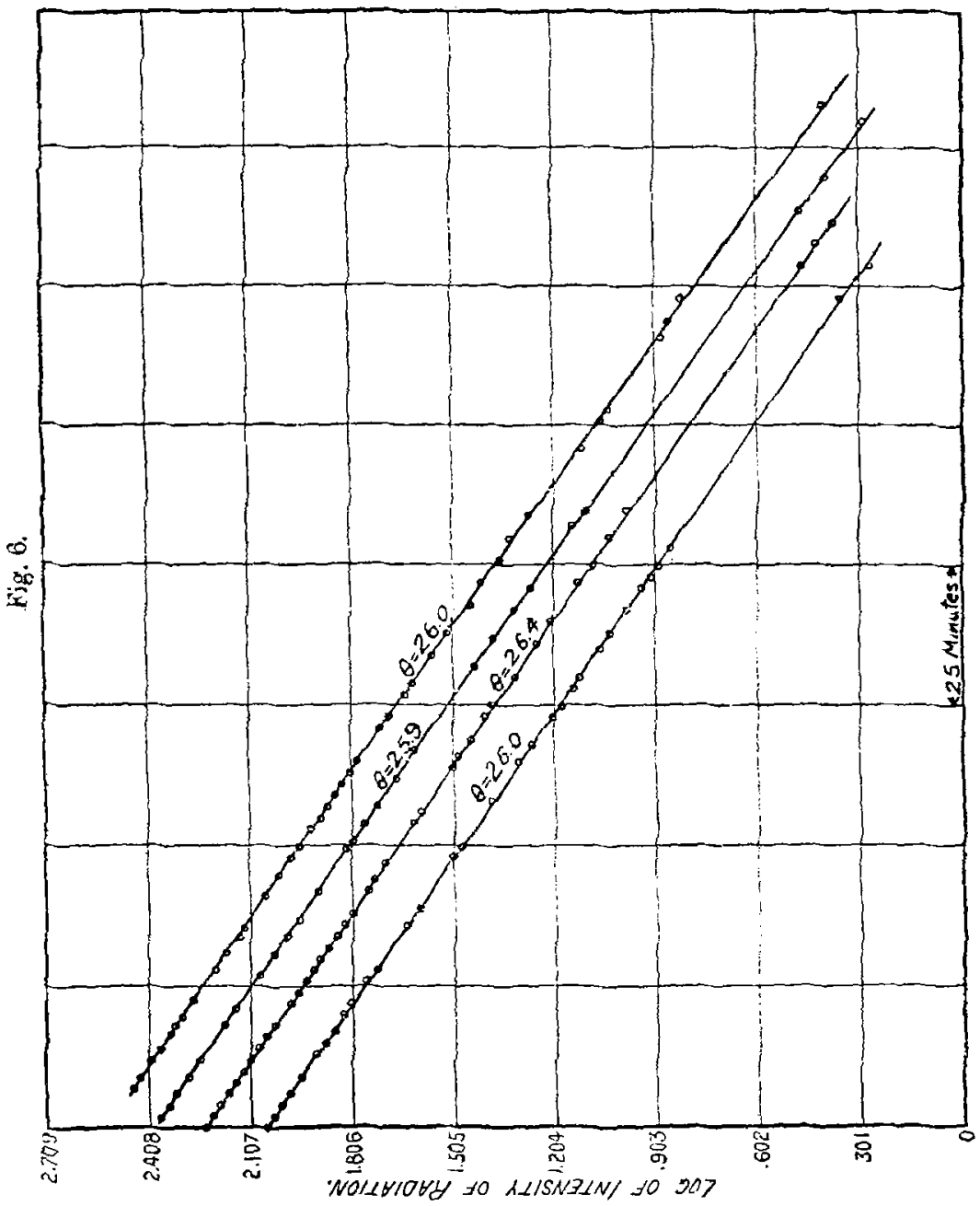

certain, and a mean of a large number of other values obtained would indicate that $25 \cdot 8$ minutes may be a trifle too small. It seems certain, however, that the period of radium $B$ is very nearly 26 minutes.

The theoretical values in the following table were obtained by assuming that only two changes take place in the aetive 
deposit; and that the periods of these are twenty-six and nineteen minutes respectively.

\begin{tabular}{|c|c|c|c|c|}
\hline \multirow{2}{*}{ Time. } & \multicolumn{2}{|c|}{ Long Exposure. } & \multicolumn{2}{c|}{ Short Exposure. } \\
\cline { 2 - 5 } & $\begin{array}{c}\text { Observed } \\
\text { Value. }\end{array}$ & $\begin{array}{c}\text { Calculated } \\
\text { Value. }\end{array}$ & $\begin{array}{c}\text { Observed } \\
\text { Value. }\end{array}$ & $\begin{array}{c}\text { Calculated } \\
\text { Value. }\end{array}$ \\
\hline 50 & $52 \cdot 9$ & $53 \cdot 1$ & $3 \cdot 57$ & $3 \cdot 61$ \\
60 & $43 \cdot 4$ & $43 \cdot 7$ & $3 \cdot 19$ & $3 \cdot 17$ \\
70 & $35 \cdot 7$ & $35 \cdot 7$ & $\cdot 75$ & $2 \cdot 73$ \\
80 & $28 \cdot 9$ & $28 \cdot 8$ & $2 \cdot 31$ & $2 \cdot 29$ \\
100 & $18 \cdot 5$ & $18 \cdot 5$ & $1 \cdot 56$ & $1 \cdot 54$ \\
120 & $11 \cdot 6$ & $11 \cdot 6$ & $1 \cdot 01$ & $1 \cdot 00$ \\
140 & $7 \cdot 2$ & $7 \cdot 2$ & $\cdot 64$ & $\cdot 63$ \\
160 & $4 \cdot 4$ & $4 \cdot 3$ & $\cdot 395$ & $\cdot 393$ \\
180 & $2 \cdot 63$ & $2 \cdot 63$ & $\cdot 241$ & $\cdot 242$ \\
200 & $1 \cdot 59$ & $1 \cdot 58$ & $\cdot 148$ & $\cdot 147$ \\
220 & $\cdot 95$ & $\cdot 95$ & $\cdot 089$ & $\cdot 089$ \\
240 & $\cdot 56$ & $\cdot 57$ & $\cdot 054$ & $\cdot 054$ \\
260 & $\cdot 33$ & $\cdot 33$ & $\cdot 032$ & $\cdot 032$ \\
280 & $\cdot 19$ & $\cdot 20$ & $\cdot 0186$ & $\cdot 0191$ \\
& & & & \\
\hline
\end{tabular}

The early part of the curve, which is especially affected by the first rapid change in the active deposit, is still under investigation. When this is completed it may be found necessary to take a value for the period of radium $\mathrm{C}$ slightly smaller than nineteen minutes, in order to make the theoretical agree as well as possible with the experimental curve. In any case, the above close agreement between the experimental and theoretical curves, added to the separate measurement of both periods, would seem to furnish conclusive evidence that twenty-six and nineteen minutes are approximately the correct values for the periods of radium $\mathrm{B}$ and $\mathrm{C}$ respectively.

\section{Conclusions.}

The above experiments would seem to prove :-

(1) That temperatures between $700^{\circ}$ and $1100^{\circ} \mathrm{C}$. do not permanently affect the rate of decay of the active deposit from radium.

(2) 'That radium $\mathrm{B}$, and not radium $\mathrm{C}$, has the longer decay period.

(3) That the previous values of twenty-eight and twentyone minutes are both too large for the decay periods of radium $\mathrm{B}$ and $\mathrm{C}$ respectively, and that twenty-six and nineteen minutes are much closer to the true values.

In conclusion, I take pleasure in expressing my indebtedness to Professor Rutherford for his many valuable suggestions and kind supervision of this work.

Macdonald Physics Bujlding,

McGill University, Montreal, Sept. 25, 1905. 